\title{
DIE DEKALOOG AS BESTANDDEEL VAN DIE VROEG-CHRISTELIKE LITURGIE.
}

By enige ondersoek na die samestelling van die liturgie van die eerste Christene, moet daar uit die staanspoor rekening gehou word met twee vormende elemente. Die eerste hiervan is die liturgiese gebruike van die Tempel en die Synagoge en tweedens, die uitsprake van Jesus en die Apostele.

Om die mate van die invloed van die Joodse godsdiensvorme op die christelike te bepaal, moet ons ons duidelik voorstel dat die Christene in Jerusalem, ná die kruisiginǵ van die Here, nog steeds die Tempel en die Synagoge beskou het as die aangewese plekke vir hul gods86 
dienstige samekoms.') Daarnaas het hulle ook huis-samekomste gehou vir lering, gebed en broodbreking.") Maar laasgenoemde was nie 'n spesifieke christelike ontwikkeling nie; huis-samekomste was reeds gebruiklik in die synagogale sfeer van die Joodse godsdiens. ${ }^{3}$ ) Van Jesus het die dissipele ook nie 'n ander voorbeeld of aanwysing gehad nie. Inteendeel, Hy het die Joods-godsdienstige praktyke ten volle nageleef, selfs elke Sabbat na die Synagoge gegaan ${ }^{4}$ ) en was net soos elke Jood van sy tyd, vervul met 'n besondere agting vir die Tempel. Nie alleen het $\mathrm{Hy}$ dit op die gesette tye gereeld besoek nie, maar uit onopsetlike mededelinge van die Evangelie blyk dit dat by die nadering van sy dood, sy besoek en gebondenheid aan die Tempel toegeneem het.") Die instelling van Tempel en Synagoge het $\mathrm{Hy}$ in ere gehou, soos sy reiniging van die Tempel en sy optrede in die Synagoges getuig.

Dir is begryplik dat die ecrste Christene Hom hierin sou volg in weerwil van die toenemende vyandigheid van die Tempel- en synogaleowerhede wat trouens nog tydens die lewe van Jesus openbaar is. Vir geruime tyd ná die kruisiging en hemelvaart, vergader hulle blykbaar. met die oog op aanbidding van Jesus en die viering van die gedagtenismaal, agter geslote deure; $;^{i}$ ) midlerwyl gaan egter hul besoek aan die Tempel voort. $\left.{ }^{7}\right)$

En vir die intensiteit van die vyandigheid teen die Christene te Jerusalem, sê dit veel dat Saulus briewe van die Tempelowerheid gehad het om Christene, sover as Damaskus, te gaan opspoor. Nietemin het ook Paulus sy optrede as Christen-leraar in die Synagoge begin en dan vanselfsprekend in ooreenstemming met die Synagogale liturgie. Dit het tot die laaste toe, sonder uitsondering, ook sy metode gebly om in elke stad eerstens aansluiting by die Synagoge te soek, ook nadat dit nie meer beleid was om die Evangelie uitsluitlik aan Jode te verkondig nie. $\left.{ }^{8}\right)$

Die eerste Christene te Jerusalem het ook die synagogale instellinge sonder teenspraak nagekom, waarskynlik tot die tyd van die verwoesting; in elk geval nog tot 60 n.C. toe Paulus vir die laaste maal daarheen terug is. ${ }^{9}$ ) By hierdie geleentheid het Jakobus aan hom gesê: „U sien, broeder, hoeveel duisende van Jode daar is wat gelowig geword het, en almal is yweraars vir die wet." Dit was reeds die standpunt van die Jerusalemse Christene in 50 n.C. ten tyde van die Apostelkon-

1) Hnd. 2:1 vv.; 3:1; 5:20 vv.

2) Hnd. $1: 13$ en 14. Joh. $20: 19,26$. Hnd. 5:42; 12:12 vv.

3) S. Krauss, Synagogale Altertümet. Berlin, 1922. S. 302 f.

4) Mt. 9:35; 12:9; 13:53. Luk. 4:16.

5) Vgl. o.a. Mrk. 11:11, 15, 27; 12:41; $13: 1$.

6) Joh. 20:19, 26. Vgl. ook Hnd. 12:12 vv.

7) Hnd. $2: 1$ vv.; 3:1 vv.; 5:2.

8 Hnd. 11:19; 13:5, 14 vv.

9) Hnd. 21:20 vv. 
vent. Van die onderhouding van die Wet van Moses in sy volle omvang, is die buitelandse Christene egter verskoon. ${ }^{10}$ ) Maar as die algemene opvatting oor die auteur, geadresseerdes en ontstaansdatum van die Jakobusbrief korrek is, het ons hierin ' $n$ bewys dat vir tenminste die Jode-christene in die buiteland, die godsdienstige samekomsplek nog steeds as "Synagoge" ") bekend gestaan het teen c. 65 n.C.

Hierdie noue verbondenheid van die Christene met Tempel en Synagoge, in Jerusalem en elders, kon nie nalaat nie om 'n diep merk te maak in die christeike liturgie in sy wordingsjare. ${ }^{12}$ ) Die hele verloop van die vroeg-christelike erediens toon inderdaad ook aan dat dit, met modifikasies, gevorm is getrou na die patroon van die synagogale erediens. Die hoofmomente van die laasgenoemde was naamlik gebed, Skriflesing en prediking. Die nadruk het op die Skriflesing en veral op die voorlesing uit die Wet geval. Vir die doel is die Wet verdeel in vier-en-vyftig perikope wat in reëlmatige volgorde op die Sabbat en op feesdae voorgelees is. Dit is genoem die sedra. As vaste instelling moet hierdie gebruik waarskynlik teruggevoer word op die tyd van Esra ${ }^{13}$ ) hoewel reeds in Deutr. $31: 10$ bevel gegee is daartoe. Maar naas die voorgeskrewe perikope uit die Wet, is ook uit die Profete voorgelees, egter na vrye keus en nie in vaste volgorde nie. Dit is genoem, haftorah. As instelling is dit sekerlik van jonger datum as die voorlesing uit die Wet. ${ }^{14}$ ) In elk geval was met die aanvang van die Christendom, die Joodse erediens in hierdie vorm al lank 'n gevestigde gebruik. Dit blyk reeds uit die benaming vir die Ou Testament wat ons in die boeke van die Nuwe Testament teë kom, nl. „Wet en Profete". Verder, volgens die optekening van Lukas het Jesus en ook Paulus die Sabbatsdiens in die Synagoge in hierdie vorm meegemaak. ${ }^{15}$ ) Die woorde van Jakobus tydens die Apostelkonvent, „Want. van die ou tyd af het Moses in elke stad die wat hom verkondig terwyl hy elke Sabbat in die synagoges gelees word" verwys ook daarna. ${ }^{15}$, $\mathrm{Na}$ die lees van die sedra en die haftorah is daar dan, op uitnodiging van die president, deur enigiemand uit die vergadering wat wou, gespreek. ${ }^{17}$ )

10) Hnd. .15:5-29.

11) Jak. $2: 2$. Die Afr. Vert. sit die oorspronklike lesing, synagoge, oor as ,vergadering".

12) In weerwil van die openlike vyandigheid van die Jode teen hulle, het die besoek van Christene aan die Synagoge, die Kerkvaders nog in die vierde eeu kommer berei. Vgl. Krauss, a.a.o. S. 190, 314.

13) Neh. 8. Vgl. I. ElBOGEN, Der Jüdische Gottesdienst in seiner geschichtlichen Entwicklung. Frankfurt a.M. 1931. S. $155 \mathrm{ff}$.

1.) Vgl. Elbogen, a.a.O. S. $175 \mathrm{f}$.

15) Vgl. Luk. 4:17. Hnd. 13:15. p. 241 .

16) Hnd. 15:21, Vgl. NieleN, The Earliest Christian Liturgy. London, 1941. $194 \mathrm{f}$.

17) Vir die ontstaan, en ontwikkeling van die gebruik, vgl. ElbOGEN, a.a.O. S. 
Dit was die basiese elemente van die synagogale Sabbatsdiens in die tyd van Jesus en die Apostele; dit was ook die basis van die vroegchristelike erediens. Hoewel die Nuwe Testament self al etlike aanduidinge oor die aard van die christelike samekoms bevat, ${ }^{18}$ ) is die eerste by benadering volledige beskrywing daarvan afkomstig uit Rome in 145 n.C. van Justinus die Martei.aAr. Van die christelike Sondagssamekoms gee hy die volgende beeld: „En op die Sondag is daar 'n samekoms van alger wat in die stad en op die platteland woon, op een plek; en die herinneringe van die Apostels en die geskrifte van die Profete word gelees solank as wat daar tyd is. Dan, wanneer die voorleser eindig, vermaan die voorsitter die aanwesiges en moedig hulle aan tot navolging van hierdie goeie dinge. Daarna staan ons alger saam op en bid." ${ }^{19}$ ) Origens handel die stuk oor die spesifiek christelike gebruik van die Eucharistie. waarop ons in hierdie artikel nie in die besonder kan ingaan nie. Maar dit is genoeg om aan te toon dat die formele skema van die christelike erediens besonder sterk gelyk op dié van die Synagoge.

Daar is egter een baie vername onderskeid. Gebed, voorlesing en prediking korrespondeer nagenoeg; maar waar die synagogale erediens die sedra's lees, word hier in die christelike samekoms, teen die middel van die tweede eeu, die ",herinneringe" van die Apostels gelees. Dis 'n diepgaande onderskeid. In die erediens van die Synagoge, soos in die Joodse godsdiens in die algemeen, was die Wet die alles oorheersende faktor; in die oorsig van Justinus word die Wet nie eers genoem nie, behalwe in $n$ opmerking in verband met die doop : ..... om ernstig te bid vir onsself en vir hom wat verlig is ('d.i. die dopeling) en vir alle andere wat elders is, sodat ons, nadat ons die waarheid geleer het, beskou kan word as mense wat 'n goeie lewenswandel beoefen en die gebooie onderhou ..." ${ }^{20}$. Ons kan anneem dat onder die lees van die "geskrifte van die Profete" bedoel is die hele Ou Testament "1) maar 'n selfstandige opnoem, om sy oorheersende plek aan te toon, het die Wet hier nie meer nie.

Die probleem is nou om te bepaal watter rol die Wet dan wel in die vroeg-christelike liturgie gespeel het; ons kan nie aanneem dat, gesien die lang verbondenheid van die oergemeente en die eerste sending-gemeentes met die Synagoge en die Tempel, die Wet sy plek geheel-en-al sou verloor het nie. Die beantwoording van die vraag is eers moontlik na die ondersoek van die waarde wat Jesus en die Apostels daaraan toegeken het.

18) Vgl. Hnd. 2:42; 1 Kor. $11: 17$ vv.

19) Justin. Apol. 1:67.

20) Idem ibid.

21) Vgl. J. Norman, A Handbook to the Christian Liturgy. S.P.C.K. 1944 p. 16. 
Jesus het self die Wet in beginsel aanvaar. Dit blyk al dadelik uit sy woorde: „Moenie dink dat Ek gekom het om die Wet en die Profete te ontbind nie. Ek het nie gekom om te ontbind nie, maar on te vervul." ${ }^{22}$ ) Ook in sy optrede het $\mathrm{Hy}$ die voorskrifte van die Wet in ag geneem; bv. toe $\mathrm{Hy}$ 'n melaatse genees het, het $\mathrm{Hy}$ hom beveel om hom aan die priester te gaan vertoon en in voldoening aan die Wet. te offer. ${ }^{23}$ )

Daar is egter twee opsigte waarin $\mathrm{Hy}$ van die gangbare Joodse opvatting van die Wet ten seerste verskil het. Die eerste was i.v:m. die offergebooie; $\mathrm{Hy}$ het daaraan slegs $\mathrm{n}$ sekondêre waarde toegeken. ${ }^{2}$ ) Die tweede was i.v.m. die mondelinge oorlewering, waarin die spesifiek fariseïese wetsbeskouing tot uiting gekom het. Hierteen het Jesus met krag gepredik en die Joodse opvattinge oor die onderhouding van vaste en wassinge, hul magiese Sabbatsbeskouing, ${ }^{25}$ ) hul voortborduringe op die mosaïese voorskrifte eenvoudig verwerp. ${ }^{26}$ )

Aan die ander kant kom mens onwillekeurig tot die oortuiging dat Hy die Wet in sy essensie gesien het in die Dekaloog, as rigsnoer van die verhouding van die mens teenoor God en sy naaste. Dit is die paslikste verklaring wat gegee kan word aan sy woorde: „Die Skrifgeleerdes en die Fariseërs sit op die stoel van Moses. Alles wat hulle dan vir julle mag sê om te onderhou, onderhou en doen dit; maar moenie volgens hulle werke doen nie, want hulle praat en doen nie." ${ }^{27}$ ) Netso is Mt. 5:21-47'n rektifiërende eksegese van die Wet deur Jesus. Die wettiese aanpaksels verwyder $\mathrm{Hy}$ van die Dekaloog, hier met name van die sesde, die sewende, die negende en tiende gebod. Trouens die hele Bergpredikasie is ' $n$ uitleg van die Dekaloog in die besondere $\sin$, die liefdes-sin, wat Jesus daaraan gee. Ook wanneer $\mathrm{Hy}$ met soveel woorde na ,.die Wet" verwys, bedoel Hy daarmee die Dekaloog. ${ }^{n}$ )

Aan hierdie beskouing van Jesus kleef iets besonders. Mrk. 12:19 vv., waarin Hy die samevatting van die Dekaloog begin met die woorde: „Hoor Israel, die Here, ons God, is 'n enige Here ..." is, wat die eerste lid betref, 'n aanhaling uit Deutr. 6:4 en 5; maar dit is ook die begin van die derde afdeling van die joodse liturgiese gebed, die Shema, wat op die Sabbat in die Synagoge gedoen is. Die tweede lid, oor die liefde teenoor die naaste, is afkomstig uit Lev. 19:18. In sy geheel het dit die basis gevorm van Jesus se Wetsbeskouing. In sy

22) Mt. 5:17,

23) Mrk. 1:40. Vgl. Lev. 14:2 vv.

21) Mrk. 12:28-34 vgl. ook Joh. 4:19 vv.

25) Mrk. 2:18 vv.; 7:1 vv.; Luk. 14:1-6. OEsterley, The Jews and Judaism during the Greek Period. London, 1941, p. 66 wys daarop dat Jesus die Jode eintlik terugbring op die sienswyse van hul eie leermeesters. Joma 8.6 leer dat in die geval van lewensgevaar, die Sabbatsgebod oor die hoof gesien kan word.

26) Mrk. 7:9-13; Luk. 11:46. Mt. 11:29 v. vgl. Mischnah Aboth 3.6. Berak. 2.2.

2) Mt. 23:1 vv. vgl. Mt. 5:17-19.

ss) Mrk. 10:19 (par), 12:29 vv. 
geheel het dit ook oorgegaan as die Wetsbeskouing van die vroeë Christendom. Een van die eerste geskrifte van die Christendom, die Didache, herhaal dit al net so as inleiding tot die uiteensetting oor die Dekaloog. ${ }^{29}$ )

Aanleiding vir die gemaklike aanname van die Dekaloog self as liturgiese element, in plek van die Sedra, is die feit dat dit ook in die Tempel-liturgie ' $n$ plek gehad het. Dekaloog en Shema is saamgelees, ${ }^{30}$ ) en soos ons reeds opgemerk het, die Shema bevat self ook veel van die Dekaloog; Rabbi Simon het selfs geoordeel dat die lees van die Tien Gebooie voor die Shema oorbodig was, aangesien die Shema dit tog bevat het. ${ }^{31}$ )

Ons kan stellig konstateer dat Jesus self die Dekaloog in die christelike erediens laat oorgaan het as plaasvervanger van Sedra en Shema. Die Shema het ook nog in belydenis-karakter gehad ${ }^{32}$ ) waarop ons weldra terug sal kom.

in Beslissende stap in die gang van die Dekaloog as liturgiese element by die vroeë Christendom, was die besluite van die Apostelkonvent. Terwyl dit nog in die Jerusalemse gemeente gebruiklik was om die Sedra's en die Shema aan te hoor, moes noodwendig ten opsigte van die christene in die sending-gebiede $n$ ander reëling getref word in verband met die aanhoor en nakoming van die Wet. In die gees van Jesus se Wetsbeskouing spreek by die geleentheid Petrus en Jakobus en waarskynlik ook Paulus en Barnabas. Besluit is om van die heidenchristene alleen te verwag dat hulle hul sal onthou van afgodsoffers. hoerery, van wat verwurg is en van bloed. ${ }^{33}$ ) Dit kom ooreen met die sg. Noagitiese Gebooie, wat die Rabbyne uit Gen. 9:4 afgelei het en wat beskou is as die eties-religieuse plig van alle mense. ${ }^{34}$ ) Die betekenis van die besluit lê hierin dat die Christene buite Jerusalem offisiëel vrygestel is van die onderhouding van die Wet in die wyere, die Joodse. sin. Uit die staanspoor sou dit op die liturgie seker nog nie in uitwerking gehad het nie. Maar sodra die synagoges vyandig begin optree teen die Christene en hul dus genoodsaak is om aparte gemeentelike samekoms te beoefen, is dit begryplik dat die voorlesing van Sedra in Shema, noudat die Wet self nie meer verpligtend is nie, sy sin sal verloor. Origens sal die christelike samekoms nog die synagogale vorm behou het.

29) Did. $1: 2$.

31) Hamburger, Rea'encyclopädie für Bibel und Talmud. Strelits, 1883. Abt. II. S. 1089. Vgl. ook ElbogeN, a.a.O., S. 24.

31) Hamburger, a.a.O. ebenda.

.2) Hamburger, a.a.O., S. 1087.

33) Hnd. $15: 5$ vv.; in besonder vss. 24-29; Hnd. 16:4; $21: 25$.

34) J. DE ZwaAn. De Handelingen der Apostelen (Serie Tekst en Ulitleg). Groningen, 1920. Bls. 111. 
In die gebiede wat deur Paulus geëvangeliseer is, al het die gemeentes ook uit Jode en heidene bestaan, het die wettisisme nie juis kans gehad op voortlewing nie, hoewel ook hy die Wet, maar dan in 'n ander sin as die Jodendom, hooggeskat het ${ }^{35}$ ) Ook van hom is dit opvallend dat hy, wat die Wet betref, die Dekaloog beskou het as Wet. Dit blyk veral uit die parenetiese gedeeltes van sy briewe.$^{36}$ ) Dieselfde skyn die geval te gewees het met die skrywer van die Hebreërbrief, Johannes en Jakobus. ${ }^{3 i}$ )

Hoe vroeg die Dekaloog in die christelike liturgie al 'n plek inge. neem het is natuurlilk nie met sekerheid te sê nie. Dis begryplik tat die liturgiese vorme vir geruime tyd op verskillende plekke nog verskillend sou wees. Maar gesien die weerspieëling daarvan in die etiek van die tyd, kan ons met ' $n$ taamlike mate van sekerheid aanneem dat dit in die laaste kwart van die eerste eeu al sy plek in die liturgie ingeneem het. Vir so 'n aanname kan ons ook bou op die oorheersende rol wat die Dekaloog in die voorligting van katechumene gespeel het. Een so 'n katechetiese handboek, wat ook liturgiese voorligting bevar, is die Didache wat in sy bestaande vorm gedateer moet word teen die einde van die eerste eeu; daarby kom nog dat geleerdes teenswoordig vrywel eenstemmig is in die beskouing dat juis die katechetiese gedeelte (cap. I Vl) oorgeneem is uit ' $n$ nog vroeëre Joods-christelike geskrif..39) En die Dekaloog, soos deur Jesus opgevat en geleer, vorm die basis van hierdie werk. Reeds die openingsparagrawe is 'n herhaling van Mrk. $12: 30,{ }^{39}$ ) En neem ons tot voorbeeld van die samehang tussen liturgie en eties-religieuse voorligting, die Joodse godsdiens, dan moet ons ook hier tot die slotsom kom dat die Didache die weerspieëling is van die vroeg-christelike liturgie.

Volstandige bewys vir die Dekaloog as liturgiese element van die christelike erediens, kom egter eers in $112 \mathrm{n}$.C. te voorskyn en dan is die mededeling nogal van heidense oorsprong. Plinius JunIOR, die propraetor van Bithynia, wend hom, soos dit steeds sy gebruik was in moeilike kwessies, tot Keiser Trajanus om voorligting in verband met die Christene. Uit sy straf-ondersoek van enkele van hulle het geblyk, ,dat die totale skuld van die christene dit was, dat hulle op 'n bepaalde dag gewoon was om voor sons -opgang saam te kom om antiphonies 'n lied tot eer van Christus te sing asof $\mathrm{Hy}$ 'n God was en 'n eed te neem, nie met die oog op een-of-ander misdaad nie, maar dat hulle nie sal steel nie, nie rowery, oorspel en troubreuk sal pleeg nie cn

35) Vgl. Rom. 7:7, 12.

$\left.{ }^{36}\right)$ Rom. 13:8-10; Gal. 5:14; Kol. 2:20-3:14.

3i) I Joh. 4:21; Jak. 4:11; Jak. 2:10 vv.; Hebr. 13:1-5.

38) Vgl. Funk-BihlmeYer, Die Apostolischen Väter. Tübingen, 1924. S.xivf. -Ook die Barnabas-brief; wat 'n hoofstuk aan die "Twee Weë" wy, gaan hierin op die genoemde oerskrif terug. Barn. XIX.

39) Did. 1, 2. Vgl. 11.1-5. 
nie sal weier om trustgelde terug te gee wanneer dit opgevra word nie; as dit verby is, was dit hulle gewoonte om uitmekaar te gaan en later weer saam te kom om deel te neem aan 'n doodgewone en onskadelike maaltyd." $\left.{ }^{+0}\right)$ Die maaltyd verwys of na die oud-christelike Agapé of die Eucharistie. Maar wat die doel van ons ondersoek betref, hier is twee baie belangrike momente. Die eerste is die feit van die antiphoniese sang tot eer vàn Christus. Ook die resiteer van die Shema in die Synagoge was antiphonies en dit was 'n gebed, 'n belydenis-gebed. Trouens op 'n tydstip is deur die Jode bepaal dat een van die responsies van die Shema hard-op en nie saggies nie gesê moes word omdat van die gekerstende Jode die gewoonte gehad het om by die responsie ook die naam van Christus te noem.") Dit herinner ons ook weer sterk aan die beskrywing van Justinus dat wanneer die dopeling in die gemeente ingelei word, hulle hul in ernstige gebed verenig vir die dopeling en vir alle mense elders sodat hulle geag mag word mense te wees wat die gebooie onderhou en so die ewigdurende saligheid mag verkry. Wat ons in Plinius se brief egter die meeste tref is die woorde, seque sacramento obstringere ne furta, ne latrocinia, ne adulteria committerent, ne fidem fallerent, ne depositum appellati abnegarent. Dit is Plinius se weergawe van deel van die Dekaloog soos hy dit verneem het van aangeklaagdes. Vir die eerste keer is hierop gewys deur J. KRAEMER ${ }^{42}$ ) wat in ne furta ne latrocinia, ne adulteria committerent, sien die sesde, sewende en agtste gebooie, maar dan in omgekeerde volgorde. Die uitdrukkinge, ne fidem fallerent, ne depositum appellati abnegarent, beskou Kraemer, m.i. tereg, as die praktiese Romein se weergawe van die negende en die tiende gebooie - ...jy mag geen valse getuienis teen jou naaste spreek nie" en .jy mag nie iets van jou naaste begeer nie." Dat die eerste tot die vyfde gebooie nie 'n indruk op Plinius gemaak het en dus ook nie in sy brief aan die Keiser genoem word nie, is begryplik; die gebooie oor die verhouding teenoor God. raak hom as administrator weinig en die betoning van eerbied teenoor die ouers kom nie so prominent na vore in die strafkode nie.

Vir die omgekeerde volgorde waarin die sesde tot die agtste gebooie deur hom genoem word, het KRAEMER as verklaring aangeneem dat Plinius meer begaan was oor die regspleging as oor die christelike liturgie en dat hy daarom dié misdade wat die regspleging as die ern-

40) Plin. Ep. X.96.9: Adfirmabant autem hanc fuisse summam vel culpae suae vel erroris, quod essent soliti stato die ante lucem convenire carmenque Christo quasi deo dicere secum invicem, seque sacramento non in scelus aliquod obstringere, sed ne furta, ne latrocinia, ne adulteria committerent, ne fidem fallerent, ne depositum appellati abnegarent: quibus peractis morem sibi-discedendi fuisse, rursusque coeundi ad capiendum cibum, promiscuum tamen et innoxium.

41) S. L. Mohler, The Bithynian Christians Again, art. in Classical Philology, vol. XXX, no. 2 , p. 166 .

42) Pling and the Early Church Service, art. in Classical P:Ilology, vol. XXIX. no. 4, p. 294. 
stigste beskou, eerste noem. Ons kan hier byvoeg dat ook sy segsmanne miskien nie juis al te presies was in hul herhaling van die Tien Gebooie nie; Christene het meermale die volgorde versteur. Die Didache, bv., het die omskrywinge en volgorde: "Jy mag nie moordpleeg nie; jy mag nie onsedelikheid bedryf nie; jy mag nie steel nie; jy mag nie doodslaan nie; jy mag nie begeer nie; jy mag nie valse getuienis spreek nie." ${ }^{43}$ ) Die Barnabasbrief -.. en ons moet in gedagte hou dat wat die „Twee Weë" betref, albei op dieselfde oerbron teruggegryp - het die volgorde: ..Jy mag nie onsedelikheid bedryf nie; jy mag die naam van God nie ydelik gebruik nie; ens." "11) Selfs die oorlewering van die Tien Gebooie in die Nuwe Testament volg nie altyd die oorspronklike indeling nie; bv. die weergawe in Mt. 19:18 vv. het by vergelyking met Ex. $20: 12$ vv: die volgorde: die sesde, sewende, agste, negende en vyfde gebooie. Die paralelle mededelinge is nog weer verskillend; Mrk. 10:19 vv. laat na mekaar volg: die sewende, sesde, agste, negende, tiende en vyfde gebooie; op sy beurt verskil Luk. 18:20 vv. weer hiervan met die opnoem van die sewende, sesde, agste, negende en vyfde gebooie agtereenvolgend. Hierdie afwykende indeling het selfs nog vroeër bestaan. Een van die Septuagint se lesings ten opsigte van Ex. $20: 13 \mathrm{vv}$. (B), lees na mekaar die sewende, agste, sesde, negende en tiende gebooie.

Maar wat vasstaan is dat die Dekaloog teen 112 n.C. in die christelike gemeente van Bithynia 'n plek ingeneem hët in die liturgie. Plinius. in weerwil van sy klaarblyklike onkunde oor die liturgie van die aangeklaagdes, versterk ons in hierdie opvatting wanneer hy die Christene se opnoem van die Dekaloog inlei met die woord sacramentum - se sacramentum obstringere. Nou kan inderdaad die woord enigiets beteken vanaf ' $n$ gewone eed tot die eed van samesweerders toe. Maar dat die propraetor in diě geval daarmee nog iets anders bedoel, is duidelik as mens die uitdrukking, ne fidem fallerent, direk daarnaas sou lees; dit kan dan verstaan word: „'n eed neem om nie 'n eed te breek nie" wat onsinnig is. ${ }^{45}$ ) En dan, sacramentum het vir die Romein ook nie presies dieselfde betekenis as die geswore eed nie; lg. word by voorbaat weergegee met iusiurandum. Uit 'n opmerking van Livius, waar iusiurandum en sacramentum in hul teenstellende betekenis naas mekaar gebruik word, is dit opvallend dat sacramentum eerder moet aandui, ," n plegtige onderneming". ${ }^{46}$ ) Om nou uit te maak wat PLINIUS presies bedoel het met sacramentum in hierdie verband, moet

43) Did II. 1-3.

14) Barn. XIX 4 $\sin$.

45) Vgl. Cicero, De Officiis 1.13 .39 vir die gebruik van fidem fallere in hierdie

46) Liv. XXII 38.3. Tum, quod nunquam antea factum erat, iure iurando ab tribunis militum adacti milites; nam ad eam diem nihil praeter sacramentum fuerat, iussu consulis conventuros etc. 
ons eerstens vra, watter woord sy segsman gebesig het. Lg. was Griekssprekend; hy het ongetwyfeld begin met 'n woord wat die betekenisse van belydenis en onderneming kan behels; as ons gissing reg is, is dit namelik wat hy en sy geloofsgenote met die Tien Gebooie gedoen het, want die eerste vier gebooie is, soos ook die Shema dit opgevat het, belydenis van die enigheid en almag van God; die tweede helfte is in die mond van hom wat dit naspreek, onderneming. Ons is van oordeel dat Plinius die woord homologia of die werkwoord daarvan, homologein, wat beteken belydenis en plegtige onderneming, gehoor het. In hierdie sin word die woord in II Kor. 9:13 gebesig. Puinius het as regspleger, meer aandag gehad vir die betekenis van onderneming as vir belydenis, sodat sy weergawe sal toenader tot die onderneem-begrip. Ook die bybelse taalgebruik ken homologia (homologein) in die betekenis van onderneming. Dit kom eerstens voor in die Septuagint in een lesing van Esé. 16:8 (B2) en van 1 Makk. 6:61 (S1); ander manuskripte lees in die gevalle, omosa (-en), wat ook al 'n aanduiding is van die begripsverwantskap van die twee woorde. Ook die Nuwe Testament gebruik die woord in hierdie betekenis. ${ }^{4 i}$ )

Homologia (homologein) is dus die woord wat deur Plinius verneem is; die liturgiese sin van ",belydenis" gaan hom nie aan nie; die edelike wel. In sy skrywe aan Trajanus, gee hy sy indruk van die Dekaloog en die gebruik daarvan deur die Christene met seque sacramento obstringere weer. Maar agter sacramentum kan ons nog steeds die belydenis-karakter lees wat aan die Shema, met sy gedeeltelike opname van die Dekaloog, verbonde was. Op die aanwysing van Jesus en die Apostels, gedistilleer uit die synagogale liturgiese instellinge van Shema en Sedra, het die Dekaloog vroeg reeds liturgiese bestanddeel geword van die christelike erediens.

A. S. GEYSER. 